\title{
Genetic Mapping in Streptomyces clavuligerus by Protoplast Fusion
}

\author{
By G. T. ILLING, ${ }^{1} \dagger$ I. D. NORMANSELL ${ }^{2}$ AND J. F. PEBERDY ${ }^{1 *}$ \\ ${ }^{1}$ Department of Botany, Microbial Biochemistry and Genetics Group, \\ University of Nottingham, Nottingham NG7 2RD, UK \\ ${ }^{2}$ Fermentation Development, Beecham Pharmaceuticals, Clarendon Road, Worthing, \\ West Sussex BN14 8QT, UK
}

(Received 24 October 1988; revised 12 April 1989; accepted 24 April 1989)

\begin{abstract}
The development of a protoplast manipulation protocol for the industrially important bacterium Streptomyces clavuligerus, which produces the $\beta$-lactamase inhibitor clavulanic acid, made possible a preliminary genetic mapping study based on protoplast fusion crosses. A preliminary position for 11 markers on the $S$. clavuligerus genetic map is proposed. Fusion progeny were characterized by random spore analysis because the markers present in the strains were not amenable to the conventional four-on-four selection procedure. Whilst the resulting map is similar to that derived by conjugation for $S$. clavuligerus and $S$. coelicolor, further analysis of the markers is required to confirm these observations.
\end{abstract}

\section{INTRODUCTION}

Recombination in streptomycetes was first demonstrated in Streptomyces coelicolor (Sermonti \& Spada-Sermonti, 1955). However, it was the introduction of protoplast fusion methods (Hopwood et al., 1977; Baltz, 1978) that provided the impetus for genetic crossing in a broader range of these organisms, in which the application of conjugation had not been feasible, e.g. S. fradiae (Baltz, 1980) and Nocardia lactamdurans (Wesseling \& Lago, 1981). Knowledge of the genetic map locations of antibiotic genes should be useful for interspecific hybrid formation, for directed mutagenesis using selectable markers closely linked to the antibiotic structural and regulatory genes, and for gene amplification by classical and recombinant DNA techniques (Queener \& Baltz, 1979; Hopwood \& Chater, 1984).

Genetic recombination between auxotrophically marked strains of $S$. clavuligerus (ATCC 27064) following conjugation has been described (Aharonowitz \& Demain, 1977), and subsequently a genetic map of fourteen markers was established (Kirby, 1978). A series of protoplast fusion crosses with $S$. clavuligerus was made in this laboratory primarily to identify suitable model crosses to study the enhancement of recombination (Illing, 1987); however, the resulting data permitted the preliminary location, reported here, of eleven new genetic markers on a chromosomal map. The validity of this map needs confirmation using conjugation crosses.

\section{METHODS}

Isolation of mutants. Auxotrophic and drug-resistant mutants were isolated mainly using UV irradiation. A few were obtained following $N$-methyl- $N^{\prime}$-nitro- $N$-nitrosoguanidine or ethyl methanesulphonate treatment (Illing, 1987). The sandwich layer technique (Saunders et al., 1982) was used to isolate drug-resistant mutants that could not be recovered by direct selection. Mutants with altered sulphur utilization were isolated using the method of Arst (1968).

Protoplast fusion. Protoplasts were isolated by the method described in the accompanying paper (Illing et al., 1989). Equal volumes $(10 \mathrm{ml})$ of the protoplast suspension $\left(1 \times 10^{7}\right.$ or $1 \times 10^{8}$ protoplasts $\left.\mathrm{ml}^{-1}\right)$ were mixed and

Present address: Fermentation Development Department, Glaxochem Ltd, North Lonsdale Road, Ulverston, Cumbria LA12 9DR, UK. 
centrifuged $(2000 \mathrm{~g}, 10 \mathrm{~min}$ ) and the pellet was resuspended in the small volume of medium P + BSA (Illing et al., 1989) remaining when the supernatant was removed. Then $1 \mathrm{ml}$ medium $P$ (Illing et al., 1989), without BSA, containing $33 \%(w / v)$ polyethylene glycol was gently added to the protoplasts and the suspension was carefully mixed. After $2 \mathrm{~min}, 4 \mathrm{ml}$ medium $P$ without BSA was added and the protoplasts were recovered by centrifugation. The protoplasts were washed in medium $P$, and finally resuspended in $1 \mathrm{ml}$ of this solution. The suspension was serially diluted and $100 \mu \mathrm{l}$ samples of the dilutions with $10^{8}$ and $10^{7}$ protoplasts $\mathrm{ml}^{-1}$ were inoculated onto solid $\mathrm{R} 6$ medium (Illing et al., 1989), supplemented with the specific requirements of the strains. Control platings of the fusion mixture and the individual protoplast suspensions included $100 \mu \mathrm{l}$ of a $10^{-1}$ dilution in Tween 80 inoculated on R6, $100 \mu$ l of a $10^{-1}$ dilution inoculated on M5D ${ }^{+2}$ [M5D+ (Bailey et al., 1984), with the concentrations of yeast extract and bacteriological peptone doubled to 4 and $5 \mathrm{~g} \mathrm{l}^{-1}$, respectively] and $100 \mu \mathrm{l}$ of a mixture of protoplasts, untreated with PEG, inoculated on R6.

The cultures were incubated at $26^{\circ} \mathrm{C}$ until no further colonies appeared (7-21 d). The mycelium was scraped

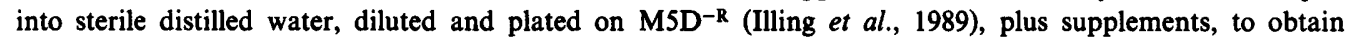
sporulation. In some experiments, benlate $\left(50 \mu \mathrm{g} \mathrm{ml}^{-1}\right)$ was used to prevent fungal contamination. Sporulation occurred after 7-14 d, and these cultures were used to prepare spore suspensions in sterile distilled water. The suspensions were filtered through glass wool to remove mycelial fragments. Spores were also resuspended in $20 \%$ $(\mathrm{w} / \mathrm{v})$ sucrose and maintained at $-20^{\circ} \mathrm{C}$.

The genotypes of progeny derived from crosses were identified by the analysis of randomly isolated spores; suspensions were plated on M5D $\mathrm{D}^{+2}$ at dilutions to give single colonies. Colonies were isolated to prepare master plates which could be replicated on to diagnostic media for characterization. The data were analysed using the Genetics.p or GENETICS computer programs (Illing \& Onions, 1986; Illing, 1987). The frequency of recombination was calculated from the ratio of the number of progeny in a recombinant class to the total number of progeny tested.

\section{RESULTS}

\section{Protoplast fusion in $S$. clavuligerus}

Fourteen protoplast fusion crosses were made (Table 1). Because of leakiness with some of the genetic markers in the strains used, it was necessary to recover and analyse between 200 and 400 random spore isolates. These crosses generated recombination data for the 11 mutations involved, but it was not possible to score the $\arg A 1$ marker because it was too leaky. The markers cys $A 14$, cys $A 44$, cys $A 46$ and cys $A 48$ were found to be allelic as were $t h r A 2$ and $t h r A 8$. The data were analysed in a pair-wise fashion and used to establish a preliminary linkage map. Where only single values for recombination frequency are available the relative positions of markers must be regarded as tentative.

A sample of 260 random isolates was tested for reversion at each mutant site; no reversion was found. A more exhaustive analysis for reversion could only be carried out with strains which had tight mutations, i.e. 12-8, 12-19, 12-132 and 12-143, and in each case the reversion frequency was less than 1 in $10^{7}$.

\section{Construction of a preliminary genetic map}

The data were used to assign the eleven genetic markers to preliminary positions on a $S$. clavuligerus genetic map (Fig. 1). A summary of the recombination data is given in Table 2 . Greatest significance was placed on the crosses which exhibited allele ratios which most closely approached unity (Table 3). Divergence from unity may reflect different capacities of protoplast regeneration, sporulation exhibited by the strains or differential selective pressure against the different markers.

The markers on the map are positioned at equal distances from each other since recombination data from protoplast fusion crosses do not accurately assign distances on a linkage map (Keller et al., 1983, 1985; Hopwood et al., 1985).

The cross between 12-132 (proAl acrA6) and 12-143 (hypAl cysA46), which was repeated several times, provided a basis for the map with an order (clockwise) of proAl, acrA6, hyp $A 1$ cys $A 46$. Further markers could then be positioned on the map by a systematic analysis of additional recombination data for these and other markers.

$\operatorname{pro} A$ cys $A$; pro $A$ cys $B$; cys $A$ cys $B$. The recombination frequencies between pro $A$ and $\operatorname{cys} A$ varied greatly. A notable feature was that combination of $c y s A$ and $c y s B$ in a cross appeared to 


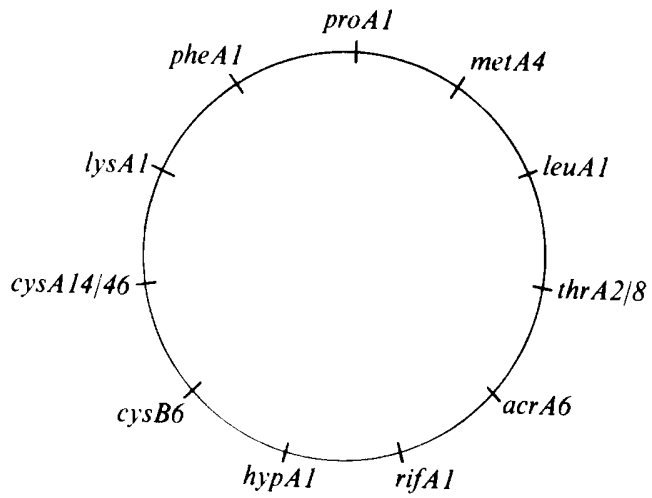

Fig. 1. Preliminary genetic map of $S$. clavuligerus.

Table 1. Protoplast fusion crosses

\begin{tabular}{|c|c|c|c|c|c|}
\hline Cross & Strain & Genotype* & & Strain & Genotype* \\
\hline $\mathrm{Cl}$ & $12-124$ & (proAl cysB6) & $x$ & $12-143$ & (hypAl cysA46) \\
\hline $\mathrm{C} 2$ & $12-125$ & (proAl rifAl) & $x$ & $12-143$ & (hypA1 cys $A 46)$ \\
\hline $\mathrm{C} 3$ & $12-132$ & (proAl acrA6) & $x$ & $12-143$ & (hypAI cysA46) \\
\hline $\mathrm{C} 4$ & $12-124$ & (proAl cysB6) & $x$ & $12-143$ & (hypAl cysA46) \\
\hline C6 & $12-124$ & (proAl cysB6) & $x$ & $12-141$ & (hypAl cys A44) \\
\hline $\mathrm{C7}$ & $12-125$ & (proAl rifAl) & $x$ & $12-141$ & (hypA1 cys A44) \\
\hline $\mathrm{C} 9$ & $12-52$ & (pheAl cys A14) & $x$ & $12-124$ & (proAl cysB6) \\
\hline $\mathrm{C} 10$ & $12-52$ & (pheAI cysA 14) & $x$ & $12-132$ & (proA1 acrA6) \\
\hline $\mathrm{C} 14$ & $12-132$ & (proAl acrA6) & $x$ & $12-143$ & (hypAl cys A46) \\
\hline CF1 & $12-14$ & (argAl pheAl) & $x$ & $12-74$ & (proAl metA4) \\
\hline CF2 & $12-14$ & (argAl pheAI) & $x$ & $12-75$ & (proAl leuAl) \\
\hline CF4 & $12-14$ & (argAl pheAl) & $x$ & $12-77$ & (proAl thrA2) \\
\hline CF5 & $12-23$ & $(\arg A I$ met $A 4)$ & $x$ & $12-75$ & (proAl leuAl) \\
\hline CF6 & $12-91$ & (proAl thrA8) & $x$ & $12-151$ & (lysA1 cysA48) \\
\hline
\end{tabular}

* Auxotrophic requirements: arg, arginine; cys, cysteine; hyp, hypoxanthine; leu, leucine; lys, lysine; met, methionine; phe, phenylalanine; pro, proline; thr, threonine. Inhibitor resistance : acr, acriflavine; rif, rifampicin.

depress the overall recombination frequency exhibited. Additionally, the cys $A$ cys $B$ recombinant colonies could not be recognized using a simple plate test. It has been shown that cys mutations reduce protoplast regeneration frequencies (Illing, 1987) and possibly sporulation, thus affecting the recovery or detection of $\operatorname{cys} A$ cys $B$ recombinants. Excluding the recombination values from crosses combining both these markers significantly reduced the variation and gave a median recombination frequency for $\operatorname{pro} A$ and $\operatorname{cys} A / B$ of $15.9 \%$. This figure was on the boundary of tight linkage suggested by Hopwood (1972) and indicated that the lys $A$ and phe $A$ markers were located between them, lys $A$ being closer to pro $A$ than phe $A$. Where cys $A$ and cys $B$ were analysed in the same cross they appeared to be very tightly linked and inseparable at the level of recombination detected. The exception was cross $C 9$, which indicated that phe $A$ maps closer to $c y s A$ than it does to $c y s B$; this may reflect the different genetic background for $c y s A$. The same order was not confirmed by linkage to pro $A$ but the allele ratios of pro $A$ in this cross exhibited the greatest departure from unity, possibly explaining this discrepancy.

hyp $A$ cys $A$; hyp $A$ cys $B$. Recombination frequencies indicated that $\operatorname{cys} A$ and $\operatorname{cys} B$ mapped closer to the hypA marker than proA.

hypA proA. Most of the crosses indicated that proA and hypA were unlinked. Although in some cases the data for proA-cys $A$ and $\operatorname{proA}-$ hyp $A$ may suggest that hyp $A$ was closer to pro $A$ than cys $A$, when the results from each cross were considered this hypothesis was not substantiated. 
Table 2. Recombination data obtained from $S$. clavuligerus protoplast fusion crosses

\begin{tabular}{|c|c|c|c|c|c|c|c|c|c|c|c|c|c|c|}
\hline \multirow[b]{2}{*}{ Markers } & \multicolumn{14}{|c|}{ Recombination frequency ( $\%$ ) } \\
\hline & $\mathrm{Cl}$ & $\mathrm{C} 2$ & $\mathrm{C} 3$ & C4 & $\mathrm{C} 6$ & C7 & C9 & $\mathrm{ClO}$ & $\mathrm{C} 14$ & CF1 & CF2 & CF4 & CF5 & CF6 \\
\hline proA cys $A$ & $1 \cdot 2$ & 18.9 & $28 \cdot 1$ & 0.8 & 0.8 & 20.8 & $14 \cdot 7$ & $10 \cdot 0$ & $11 \cdot 2$ & - & - & - & - & 15.9 \\
\hline cys $A$ cys $B$ & 0 & - & - & 0 & 0 & - & 3.9 & - & - & - & - & - & - & - \\
\hline hypA cysA & 6.5 & 4.6 & 3.5 & $9 \cdot 6$ & $8 \cdot 1$ & 4.6 & - & - & $2 \cdot 7$ & - & - & - & - & - \\
\hline hypA proA & $5 \cdot 4$ & $15 \cdot 1$ & 4.6 & 8.9 & $7 \cdot 3$ & $19 \cdot 2$ & - & - & 10.8 & - & - & - & - & - \\
\hline hyp $A$ cysB & 6.5 & - & - & 9.6 & $8 \cdot 1$ & - & - & - & - & - & - & - & - & - \\
\hline cys $B$ proA & $1 \cdot 2$ & - & - & 0.8 & 0.8 & - & 11.6 & - & - & - & - & - & - & - \\
\hline proA rifA & - & $14 \cdot 3$ & - & - & - & 18.9 & - & - & - & - & - & - & - & - \\
\hline cysA rifA & - & 10.8 & - & - & - & 6.5 & - & - & - & - & - & - & - & - \\
\hline hypA rif $A$ & - & 3.9 & - & - & - & 8.9 & - & - & - & - & - & - & - & - \\
\hline proA acrA & - & - & $7 \cdot 3$ & - & - & - & - & $11 \cdot 2$ & 13.9 & - & - & - & - & - \\
\hline cys $A$ acr $A$ & - & - & $3 \cdot 1$ & - & - & - & - & $3 \cdot 5$ & $8 \cdot 1$ & - & - & - & - & - \\
\hline hypA acr $A$ & - & - & 3.5 & - & - & - & - & - & 7.7 & - & - & - & - & - \\
\hline pros pheA & - & - & - & - & - & - & 8.5 & 8.5 & - & $14 \cdot 4$ & 4.5 & $20 \cdot 1$ & - & - \\
\hline cys A pheA & - & - & - & - & - & - & $10 \cdot 0$ & $3 \cdot 1$ & - & - & - & - & - & - \\
\hline cys B phe A & - & - & - & - & - & - & $13 \cdot 1$ & - & - & - & - & - & - & - \\
\hline acrA pheA & - & - & - & - & - & - & - & $4 \cdot 2$ & - & - & - & - & - & - \\
\hline proA metA & - & - & - & - & - & - & - & - & - & 9.5 & - & - & 0.8 & - \\
\hline pheA metA & - & - & - & - & - & - & - & - & - & $19 \cdot 3$ & - & - & - & - \\
\hline proA leuA & - & - & - & - & - & - & - & - & - & - & $4 \cdot 1$ & - & 3.9 & - \\
\hline pheA leuA & - & - & - & - & - & - & - & - & - & - & $6 \cdot 2$ & - & - & - \\
\hline proA thrA & - & - & - & - & - & - & - & - & - & - & - & 8.9 & - & $13 \cdot 5$ \\
\hline pheA thrA & - & - & - & - & - & - & - & - & - & - & - & $16 \cdot 0$ & - & - \\
\hline metA leuA & - & - & - & -- & - & - & - & - & - & - & - & - & $3 \cdot 1$ & - \\
\hline cys $A$ thrA & - & - & - & - & - & - & - & - & - & - & - & - & - & $21 \cdot 6$ \\
\hline cysA lys $A$ & - & - & - & - & - & - & - & - & - & - & - & - & - & $7 \cdot 2$ \\
\hline lysA proA & - & - & - & - & - & - & - & - & - & - & - & - & - & 11.7 \\
\hline lys $A$ thrA & - & - & - & - & - & - & - & - & - & - & - & - & - & $20 \cdot 5$ \\
\hline All classes & 6.5 & $20 \cdot 4$ & $9 \cdot 2$ & 9.6 & $8 \cdot 1$ & $24 \cdot 6$ & $17 \cdot 0$ & $12 \cdot 7$ & 16.9 & $21 \cdot 6$ & $7 \cdot 4$ & $23 \cdot 5$ & 3.9 & 25.8 \\
\hline
\end{tabular}

Table 3. Allele ratios for the mapping crosses

Number of progeny

\begin{tabular}{|c|c|c|c|c|c|c|c|c|c|c|c|c|c|c|c|}
\hline \multirow[b]{2}{*}{ Marke } & \multirow{2}{*}{$\begin{array}{l}\text { Cross } \\
\text { no. . }\end{array}$} & \\
\hline & & $\mathrm{Cl}$ & $\mathrm{C} 2$ & $\mathrm{C} 3$ & $\mathrm{C} 4$ & C6 & C7 & C9 & $\mathrm{C} 10$ & $\mathrm{C} 14$ & $\mathrm{CF} 1$ & CF2 & CF4 & CF5 & CF6 \\
\hline & $\begin{array}{l}\text { proA A }^{+} \\
\text {proA }\end{array}$ & $\begin{array}{l}101 \\
159\end{array}$ & $\begin{array}{l}142 \\
118\end{array}$ & $\begin{array}{r}89 \\
171\end{array}$ & $\begin{array}{l}130 \\
130\end{array}$ & $\begin{array}{l}144 \\
116\end{array}$ & $\begin{array}{r}179 \\
81\end{array}$ & $\begin{array}{r}41 \\
218\end{array}$ & $\begin{array}{r}5 \\
255\end{array}$ & $\begin{array}{l}104 \\
156\end{array}$ & $\begin{array}{r}34 \\
230\end{array}$ & $\begin{array}{r}84 \\
402\end{array}$ & $\begin{array}{r}5 \\
208\end{array}$ & $\begin{array}{l}107 \\
152\end{array}$ & $\begin{array}{r}220 \\
44\end{array}$ \\
\hline & $\begin{array}{l}\text { cys } A^{+} \\
\text {cys } A\end{array}$ & $\begin{array}{l}158 \\
102\end{array}$ & $\begin{array}{l}159 \\
101\end{array}$ & $\begin{array}{r}186 \\
74\end{array}$ & $\begin{array}{l}128 \\
132\end{array}$ & $\begin{array}{l}114 \\
146\end{array}$ & $\begin{array}{l}125 \\
135\end{array}$ & $\begin{array}{r}186 \\
73\end{array}$ & $\begin{array}{r}237 \\
23\end{array}$ & $\begin{array}{r}161 \\
99\end{array}$ & $\begin{array}{l}- \\
-\end{array}$ & $\begin{array}{l}- \\
-\end{array}$ & $\begin{array}{l}- \\
-\end{array}$ & $\begin{array}{l}- \\
-\end{array}$ & $\begin{array}{r}50 \\
214\end{array}$ \\
\hline & $\begin{array}{l}\text { cys } B^{+} \\
\text {cys } B\end{array}$ & $\begin{array}{l}102 \\
158\end{array}$ & - & - & $\begin{array}{l}132 \\
128\end{array}$ & $\begin{array}{l}146 \\
114\end{array}$ & $\begin{array}{l}- \\
-\end{array}$ & $\begin{array}{r}67 \\
192\end{array}$ & - & - & - & - & - & - & - \\
\hline & $\begin{array}{l}\text { hyp A+ } \\
\text { hypA }\end{array}$ & $\begin{array}{r}173 \\
87\end{array}$ & $\begin{array}{l}155 \\
105\end{array}$ & $\begin{array}{r}183 \\
77\end{array}$ & $\begin{array}{l}153 \\
107\end{array}$ & $\begin{array}{l}135 \\
125\end{array}$ & $\begin{array}{l}131 \\
129\end{array}$ & - & - & $\begin{array}{r}166 \\
94\end{array}$ & - & - & - & - & - \\
\hline & $\begin{array}{l}\text { rifA } A^{+} \\
\text {iifA }\end{array}$ & - & $\begin{array}{l}111 \\
149\end{array}$ & - & - & - & $\begin{array}{l}150 \\
110\end{array}$ & - & - & - & - & - & - & - & - \\
\hline & $\begin{array}{l}a c r A^{+} \\
\text {acrA } A\end{array}$ & - & - & $\begin{array}{r}76 \\
184\end{array}$ & - & - & - & - & $\begin{array}{r}26 \\
234\end{array}$ & $\begin{array}{r}90 \\
170\end{array}$ & - & - & - & - & - \\
\hline & phe $A^{+}$ & - & - & - & - & - & - & $\begin{array}{r}208 \\
51\end{array}$ & $\begin{array}{r}241 \\
19\end{array}$ & - & $\begin{array}{l}284 \\
236\end{array}$ & $\begin{array}{r}161 \\
70\end{array}$ & $\begin{array}{l}65 \\
48\end{array}$ & - & - \\
\hline & met $^{+}$ & - & - & - & - & - & - & - & - & - & 217 & - & - & 154 & - \\
\hline & metA & - & - & - & - & - & - & - & - & - & 47 & - & - & 105 & \\
\hline & $\begin{array}{l}\operatorname{leu}_{A}{ }^{+} \\
\operatorname{leu}\end{array}$ & - & - & - & - & - & - & - & - & - & - & $\begin{array}{r}80 \\
406\end{array}$ & $\begin{array}{l}- \\
-\end{array}$ & $\begin{array}{l}109 \\
150\end{array}$ & $\begin{array}{l}- \\
-\end{array}$ \\
\hline & $\begin{array}{l}t h r A^{+} \\
t h r A\end{array}$ & - & - & $\begin{array}{l}- \\
-\end{array}$ & - & - & - & - & - & - & - & $\begin{array}{l}- \\
-\end{array}$ & $\begin{array}{r}22 \\
191\end{array}$ & - & $\begin{array}{r}249 \\
15\end{array}$ \\
\hline & $y s A^{+}$ & - & - & - & - & - & - & -- & - & - & - & - & - & - & 45 \\
\hline & lys $A$ & - & - & - & - & - & - & - & - & - & - & - & - & - & 219 \\
\hline
\end{tabular}


The order (anti-clockwise) of proA cys $A$ hypA was also confirmed by recombination data for cys $A$ and hyp $A$ and for acr $A$ and $\operatorname{rif} A$.

proA rif $A ;$ cys $A$ rif $A ;$ hyp $A$ rif $A$. Crosses $\mathrm{C} 2$ and $\mathrm{C} 7$ were used to order these markers. The former gave allele ratios closest to unity and was favoured where discrepancies arose. Of these three markers ( $p r o A$, cys $A$, hyp $A$ ) pro $A$ exhibited the lowest degree of linkage to rif $A$ and in cross $\mathrm{C} 7$ the two markers appeared to be unlinked. The order indicated by cross $\mathrm{C} 2$ was (anticlockwise) cys $A$ hyp $A$ rif $A$. In both crosses cys $A$ exhibited tighter linkage to hyp $A$ than to rif $A$.

pro $A$ acr $A$; cys $A$ acr $A$; hyp $A$ acr $A$. Results from the three crosses $(\mathrm{C} 3, \mathrm{C10}, \mathrm{C14})$ suggest two possible orders, with the acr 66 and hypAI markers in reversed positions. However, based on allele ratios which most closely approached unity the data support an anti-clockwise order proAI cys $A 46$ hypAl acrA6. Other data (Illing, 1987) favoured this orientation in a ratio of $7: 1$. The ordering of markers $a c r A$ and rif $A$ was done by considering crosses $\mathrm{C} 2$ and $\mathrm{C} 14$ (fusions with the best allele ratios for the markers concerned) and the two following orders are proposed (anticlockwise order): (a) cys A hypA acrA rif A proA; (b) cys A hypA rif A acrA proA. Configuration (b) fitted the data most accurately with only one discrepancy, whereas $(a)$ had three. Further crosses would be required to confirm this order.

proA phe $A$; cys $A$ phe $A$; cys $B$ phe $A$. Using the data from cross $C 9$ phe $A$ was placed between pro $A$ and $c y s A$. The results from this cross suggested that $c y s B$ mapped further away from phe $A$ than did the cys $A$ marker. This was not consistent with the order with respect to proA but this marker in this cross exhibited the most aberrant allele ratio.

acr $A$ phe $A$. The data from cross $\mathrm{C} 10$ appeared to show linkage between phe $A$ and $a c r A$. Significance was not attached to this result because the allele ratios were extremely aberrant, possibly due to sporulation problems with strain 12-52.

proA met $A$, and other combinations. The order (moving clockwise) proA metA leuA thrA was suggested for the following reasons. Assuming the validity of the preliminary order (moving clockwise) lys $A$ pheA proA, based on cross CF6 in which pro $A$ mapped closer to phe $A$ than did lys $A$, the order derived from cross CF2, phe A proA leuA, was orientated to give the overall order lys $A$ phe $A$ proA leuA. Using the results of cross CF5, i.e. proA metA leuA, to build on this order, the map was extended to: lys $A$ phe $A$ proA met $A$ leuA.

Finally, the thr $A$ locus was placed between $\operatorname{leu} A$ and acr $A$ because the recombination frequencies for proA and $\operatorname{th} A(8.9 \%, 13.5 \%)$ were greater than those for $\operatorname{pro} A$ and $\operatorname{leu} A(3.9 \%$, $4.1 \%$ ) but less than those for pro $A$ and $a c r A(13.9 \%)$. The data showed that phe $A, \operatorname{cys} A$ and $l y s A$, all proposed on the opposite side of the linkage map to $\operatorname{thr} A$, were unlinked to $\operatorname{thr} A$. The 3 o'clock region of the map (particularly) requires further crosses to fully validate the order of leuAthrA $\operatorname{acr} A$ rif $A$.

The allele ratios associated with the crosses used in the construction of the preliminary genetic map of $S$. clavuligerus are given in Table 3 . Where aberrant allele ratios were observed this was largely due to the unequal recovery of the parental strains. Thus in cross $\mathrm{C} 10$ the ratio of $226: 1$ was probably due to the low recovery of strain 12-52 arising from its poor sporulation.

In the crosses where sufficient data were obtained to draw firm conclusions, none of the markers exhibited a marked selective advantage or disadvantage thereby dramatically affecting their frequency of occurrence in the progeny of the cross. Therefore, to prevent aberrant recombination frequencies distorting the order of the markers on the map, crosses exhibiting allele ratios closest to unity were used. The allele ratios of most auxotrophic markers showed a slight bias towards prototrophy, e.g. cys $A(+:-1.41: 1)$, hypA $(+:-1.51: 1)$, proA $(+:-1 \cdot 37: 1)$. Recombination frequencies between particular markers were markedly perturbed by one fusion, i.e. cross $\mathrm{Cl} 0$, from which aberrant allele ratios were obtained. This cross highlighted how combinations of disadvantageous auxotrophic markers gave a much greater overall deleterious effect than the two markers acting independently. The drugresistance marker $\operatorname{acr} A$ was shown to be slightly advantageous (acr $A+:-1: 1 \cdot 28)$. 


\section{DISCUSSION}

The procedure adopted for the analysis of the first set of fusion crosses was dictated by the fact that the strains were not amenable to standard four-on-four analysis (Hopwood et al., 1985). In some cases colonies developed from spores inoculated onto selective media, indicating that certain markers were leaky. This caused difficulty in their characterization by the direct selection method, a problem also observed in S. rimosus (Friend \& Hopwood, 1971).

Two hundred and sixty isolates were considered to be a sufficiently large sample for analysis. The randomly selected recombinants were retested to confirm results. Back mutation of all the genes analysed was significantly lower than the recombination frequencies observed and was not a factor in the crosses described. Regenerants derived from untreated mixtures of parental protoplasts did not include recombinants. No selective pressure was applied against the parental strains in the recovery of the cross progeny. Thus their number complicated the analysis of the data in the pair-wise data tables.

Protoplast fusion has been shown to distort genetic maps because of the ensuing participation of whole chromosomes and the consequent increase in the level of recombination possible, leading to loosened linkage and near-random assortment of genotypes in some crosses (Hopwood et al., 1977; Pigac et al., 1982; Hranueli et al., 1983; Keller et al., 1983; Hopwood \& Chater, 1984). However, this loosened genetic linkage does not itself produce ambiguity in the cases analysed, e.g. S. coelicolor (Hopwood \& Wright, 1978), S. lividans (Hopwood et al., 1983) and $S$. rimosus (Hranueli et al., 1983).

A genetic map of $S$. clavuligerus has been previously established by a series of conjugative crosses (Kirby, 1978) and is similar to that presented here. As the strains used in producing the earlier map were not available to us, complementation studies could not be carried out and therefore it is not possible to discuss the basis of the differences between the two linkage maps and the significance of conjugation and protoplast fusion as mechanisms for recombination in $S$. clavuligerus. Despite insufficient information on the complementary nature of phenotypically similar mutations in $S$. coelicolor (Hopwood et al., 1985) and $S$. clavuligerus there are some similarities between the maps of the two species. When more data are available one would expect to observe similarities of gene distribution on the two chromosomal maps, a phenomenon observed with other streptomycetes (Rhodes, 1986).

This work was supported by a SERC CASE award in collaboration with Beecham Pharmaceuticals UK to G.T.I.

\section{REFERENCES}

Aharonowitz, Y. \& Demain, A. L. (1977). Genetic recombination in the cephamycin producer, Streptomyces clavuligerus. European Journal of Applied Microbiology 4, 125-130.

ARST, H. N. (1968). Genetic analysis of the first steps of sulphate metabolism in Aspergillus nidulans. Nature, London 219, 268-270.

Balley, C. R., Butler, M. J., Normansell, I. D., Rowlands, R. T. \& Winstanley, D. J. (1984). Cloning a Streptomyces clavuligerus genetic locus involved in clavulanic acid biosynthesis. Biotechnology 2, 808-811.

BALTZ, R. H. (1978). Genetic recombination in Streptomyces fradiae by protoplast fusion and cell regeneration. Journal of General Microbiology 107, 93-102.

BALTZ, R. H. (1980). Genetic recombination by protoplast fusion in Streptomyces. Developments in Industrial Microbiology 21, 43-54.

FrIEND, E. J. \& HopwoOd, D. A. (1971). The linkage map of Streptomyces rimosus. Journal of General Microbiology 68, 187-197.
HopwOOD, D. A. (1972). Genetic analysis in microorganisms. Methods in Microbiology 7B, 2738.

Hopwood, D. A. \& Chater, K. F. (1984). Streptomyces. In Genetics and Breeding of Industrial Mircroorganisms, pp. 7-42. Edited by C. Ball. Boca Raton: CRC Press.

HoPWOOD, D. A. \& WRIGHT, H. M. (1978). Bacterial protoplast fusion: recombination in fused protoplasts of Streptomyces coelicolor. Molecular and General Genetics 162, 307-317.

HoPwOOD, D. A., WRIGHT, H. M., BIBB, M. J. \& CoHeN, S. N. (1977). Genetic recombination through protoplast fusion in Streptomyces. Nature, London 268, 171-174.

HOPWOOD, D. A., KIESER, T., Wright, H. M. \& BibB, M. J. (1983). Plasmids, recombination and chromosome mapping in Streptomyces lividans 66. Journal of General Microbiology 129, 2257-2269.

HopwOOD, D. A., BIBb, M. J., ChATER, K. F., KIESER, T., BRUTON, C. J., Kieser, H. M., LydiATE, D. J., SMITH, C. P., WARD, J. M. \& SCHREMPF, H. (1985). 
Genetic Manipulation of Streptomyces. A Laboratory Manual. Norwich: The John Innes Foundation.

Hranueli, D., Pigac, J., Smokvina, T. \& Alacevic, M. (1983). Genetic interactions in Streptomyces rimosus mediated by conjugation and by protoplast fusion. Journal of General Microbiology 129, 14151422.

ILLING, G. T. (1987). Protoplast fusion and regeneration in Streptomyces clavuligerus. PhD thesis, University of Nottingham, Nottingham.

ILling, G. T. \& ONIONS, J. P. (1986). Genetic analysis of a sexual or parasexual cross: Genetics.p. Binary 7 , 33-36.

Illing, G. T., Normansell, I. D. \& Peberdy, J. F. (1989). Protoplast isolation and regeneration in Streptomyces clavuligerus. Journal of General Microbiology 135, 2289-2297.

Keller, U., Poschmann, S., Krengel, U., KleinKAUF, H. \& KRAEPELIN, G. (1983). Studies of protoplast fusion in Streptomyces chrysomallus. Journal of General Microbiology 129, 1725-1731.

Keller, U., KRENGEL, U. \& HAESE, A. (1985). Genetic analysis in Streptomyces chrysomallus. Journal of General Microbiology 131, 1181-1191.

KIRBY, R. (1978). Genetic mapping of Streptomyces clavuligerus. FEMS Microbiology Letters 3, 177-180.
Pigac, J., Hranueli, D., Smokvina, T. \& Alacevic, M. (1982). Optimal cultural and physiological conditions for handling Streptomyces rimosus protoplasts. Applied and Environmental Microbiology 44, 11781186.

QUEENER, S. W. \& BALTZ, R. H. (1979). Genetics of industrial microorganisms. Annual Report on Fermentation Processes 3, 5-45.

RHODES, M. (1986). Genetic recombination and maps for Streptomyces. In The Bacteria, pp. 27-60. Edited by S. W. Queener \& L. E. Day. London: Academic Press.

Saunders, G., Allsop, A. E. \& Holt, G. (1982). Modern developments in mutagenesis. Journal of Chemical Technology and Biotechnology 32, 254-264. Sermonti, G. \& Spada-Sermonti, I. (1955). Genetic recombination in Streptomyces. Nature, London 176, 121.

Wesseling, A. C. \& Lago, B. D. (1981). Strain improvement by genetic recombination of cephamycin producers, Nocardia lactamdurans and Streptomyces griseus. Developments in Industrial Microbiology 22, 31-40. 